\title{
The Importance of Establishing a Mentoring System in Chinese Private Higher Education
}

\author{
Changjiang Ren \\ Department of Teaching Administration \\ Xijing University \\ Xi'an, China
}

\begin{abstract}
In order to improve and enrich teachers' professional knowledge, skills, and teaching methodology, private universities are suggested to establish the mentoring system. This is one of the most effective ways to improve faculty's quality.
\end{abstract}

Keywords-mentoring system; private university; teacher quality; mentor

\section{INTRODUCTION}

Since Chinese Reform and Opening-up policy, Chinese private universities have undergone a rapid development no matter in terms of quantity or scale, which has played a significant role in the field of educational resources, talent development and economic growth in China. However, compared with Chinese public universities, private education in China is treated differently. The development of Chinese private education was not so easy for years and always in a difficult situation, especially for the improvement of teaching quality. It is well known that the key for improving teaching quality is teaching capability and comprehensive quality of the teachers in universities. Thus, in order to compete with public universities, private universities have to establish an effective system to improve and enrich teachers' professional knowledge, skills, and teaching methodology.

In fact, most universities under Chinese educational policy have established a department called center for faculty development which aims to provide professional training to improve teachers' teaching skills and strong adaptability when being faced with different working problem through discussion around academic issues. Nevertheless, although many universities pay more attention to their center for faculty development, the center merely focus on some superficial work. It lacks of specific strategies and systematic training measures for teachers' development. In most cases, the department prefers to organize several academic lectures for groups of teachers, who are also encouraged to publish more academic papers for the purpose of professional titles promotion. Therefore, the individual development of teachers is still ignored by related departments. As private universities, they should recognize the weakness and limitation of the existing center and explore more on individuals in order to make survive and develop well. They clearly know that running and managing private universities with flexible autonomy is a competitive advantage compared with public ones. It is much easier for them to establish a system to improve the whole faculty's quality through individual ability's promotion and enhancement. The mentoring system is one of the most effective ways to improve faculty's quality. Therefore, the purpose of this article is to deeply understand the importance of establishing mentoring system in Chinese universities, especially for private universities which should be developed faster than public ones, although mentoring system in China is still at the exploratory stage.

\section{THE IMPORTANCE AND THE FORM OF MENTORING}

Mentoring has been illustrated as a kind of interactive relationship between mentors and mentees. Among the majority definitions of mentoring, a mentor is to encourage mentees to achieve their dreams and desires, offer opportunities to make mentees practice more in their work, guide mentees to be aware of unwritten rules and regulations in their working place, play the role of a professional model, and provide both personal counsel and career advice whenever is required (Johnson, 2003; Allen, Russell \& Maetzke, 1997). The mentoring process is a more experienced, knowledgeable and skilled organization members as a teacher, coach, role model and professional tutor to facilitate less experienced mentees with advice, knowledge, counsel, challenge and support, and then lead them to be a professional member in an organization (Johnson, 2003).

Mentoring system or programs has been introduced by many corporations and organizations during their daily management to enhance employees' productivity and quality since the 1980s of last century (Nash, 2003). The purpose of mentoring is to inspire and support employees to develop their own intelligence to the maximum extent which lead to the further exploration of their potential. Also, a good mentoring system is the key for an organization to achieve higher level of management (Jamshed et al. 2013). By contraries, one of the main reasons leading to the slow development or even failure of a corporation is the lacking of professional mentoring system for employees' training 
and coach or ignoring of the defects of the existing system (Memon et al. 2013). Indeed, there are many benefits of mentoring for organizations, which relate to the development of human resource, such as contribution to job performance, high productivity, motivation, satisfaction, loyalty, organizational socialization, organizational communication and retention rates (Fagenson, 1988). How? It has been demonstrated by many scholars. Firstly, under the guidance of the selected mentors, mentees could get integrated into the organization as soon as possible and get better understanding of the enterprise culture, mission and vision; secondly, as the mentoring relationship humanizes the working environment and helps mentees feel that they are one of the organization's power holders (the sense of integration and belonging), the staff is less likely to resign; thirdly, because of being encouraged in mentoring process, mentees are more like to work effectively and productively, and make contribution to their organizations; finally, with the specialized conduct to each individual during their working progress, mentors can help an individuals to complete their work with bypassing the hierarch, employees being mentored would obtain a great deal of experience with strong sense of satisfaction and less frustration than those who are not mentored (Fagenson, 1988; Memon et al. 2013; Hudson, 2010; Allen, Russell \& Maetzke, 1997).

Furthermore, mentoring system can build a knowledge exchange circle, organizational culture transmission and close relationship among employees themselves and between employees and enterprises (Wilson \& Elman, 1990). For example, a distinguished advantage provided by mentoring relationships is the direct promotion in building a health and intellectual human resources mechanism and platform for knowledge sharing and communication. Knowledge is the key driver to success for organization, which will be equipped with more competitive advantages through knowledge creation and sharing (Bryant, 2005). Moreover, to be specific, mentoring system shows the short-term benefits and long-term outcomes for organizations. Adequate support, assistance, recognition and mutual-respect brought to the staff are being regarded as short-term mentoring benefits. For the long-term outcomes, mentoring programs can not only lead mentors themselves to achieve career success as their leadership skill and personal reputation will be improved and enhanced through their daily guidance, but also motivate mentees to increase and strengthen their career outcomes (Eby et al., 2006). Thus, an increasing number of enterprises are pleasant to introduce the mentoring system to enhance their management, competitiveness and employees' quality.

Then, mentoring can be divided into formal and/or informal ways in general. Bressman, Winter \& Efraon, (2018) define the difference of formal and informal mentoring in organizations. For the formal mentoring, it normally established through the existing programs which have been designed and will be supported by the organizations from its beginning to completion. It is delivered on a level of pointto-point, and both mentors and proteges are members of the same organizations. Mentors are often endowed with the responsibility to the mentoring work include mentees evaluation, coaching process report. On the other hand, in some cases, organizational administrators might invite some experts from other organizations of the same industry to mentor their employees when required. Furthermore, in the aspect of informal mentoring, it can be regarded as a nonsystematic and voluntary way to support mentees. Under informal mentoring, the boundaries of relationship between coach and friend may be difficult to discern, because participants may communicate strategies ideas, resources and practical experience with each other. This relationship is less likely to show the formal evaluation functions. Whatever the formal or informal mentoring, Kemmis et al. (2014) indicate that both of the two forms are practiced to help employees to find their own position within organizational community and the demands of their working content.

\section{Mentoring In EduCATIONAL FIELD}

In recent years, many educational institutions, especially in western countries, also follow this trend to build the mentoring system to improve their teachers' quality, and they have achieved some positive results. The most important role of mentoring system in educational field is to mentor fresh teachers. Mentoring is a key program which provides preparations for new teachers because teaching is a complicate task and teachers will face many general or academic challenges. Actually, most of the fresh teachers would not be qualified after their university study of induction training related with education. Meanwhile, in order to become a professional, skillful and knowledgeable teacher, he or she should experience rounds of cultivation during the teaching progress, which is not able to grasp through theoretical study in the campus. (Mena, Hennissen \& Loughran, 2017). Mentoring has already been considered as a meaningful way for novice to get familiar with their profession because the required professional knowledge and basic skills are offered to pre-service teachers in order to deal with the uncertainty and complexity during work. Moreover, fresh teachers often feel stressful in the first two years in their career as a teacher. The mentoring relationship can also help to relieve novices' pressure through encouragement and support from their enterprise (Allen, Russell \& Maetzke, 1997).

From these perspectives, Richter et al. (2013) and Hudson (2010) have concluded several functions of mentoring for our better understanding about the ways in which mentoring support beginning teachers. The first one is the instructional support which assists teachers to enrich their professional knowledge and improve their teaching skills that will lead them to be a good lecture (Richter et al., 2013). It contains the assistance of curriculum planning such as the timetable and schedule, suggestions in classroom management including the strategies to manage students' learning behavior, teaching related suggestions and feedback, assist to evaluate students' assignment, and other practices that improve new teachers' teaching skills and knowledge (Richter et al., 2013; Hudson, 2010). It has been proved that this mold of support is not only to strengthen new teachers' competitive advantage, but also enhance the quality of teaching and students' cultivation. Effective 
teaching demands savvy questioning techniques through which mentors with mentees can discuss high- and lowlevel issues and assign problems in a fair way.

Secondly, mentoring can provide psychological support to beginning teachers (Richter et al., 2013). Psychological support is an important way to build mentees' confidence, listen to their bewilderment or working problems, encourage their self-esteem and increase their self-reliance. This mode of support is strongly related with the first or second year of teaching, because new teachers need to adapt new working environment (Richter et al., 2013). Psychological support is considered as a good method to improve personal wellbeing so far as reducing pressure levels and improving job satisfaction (Richter et al., 2013). Also, powerful psychological support can reduce beginning teachers' turnover rate. Thus, a powerful mentoring program is not only to increase beginning teachers' career satisfaction, but also decrease the cost of human resources (Hudson, 2010).

Thirdly, it is the role modeling. When new teachers desire to observe their mentor's classroom management and teaching skills, the function of role modeling is shown. Although new teachers have already learned the thousands of hours of teaching knowledge and skills during their universities or other educational training institutions, most of them do not have practical experiences in the real teaching situation. Now they can apply their theoretical knowledge into thinking, reflection and imitation from their observations (Richter et al., 2013; Hudson, 2010). This provides opportunities for beginning teachers to analyze practical teaching skills through an external perspective, which can provide them more references on manage classrooms and interactive techniques with students. Through offering a role model for new teachers, the observer can be involved into the teaching community and emulate how to serve as a professional (Hudson, 2010). Thus, the role modeling is different from the previous two functions. The reason is that it does not need mentors' active support. Previous literature has presented that observation of the mentors' actual teaching in classroom is also a way to learn teaching methodologies.

Finally, feedback is also the important function for mentoring beginning teachers (Hudson, 2010). Effective mentors can always point out teaching weakness clearly and give new teachers some suggestions. Besides, mentors will also review new teachers' curriculum plans, syllabus design and assignment collection from their students, and then give them oral and/or written feedback. The further feedback is to evaluate beginning teachers' learning and teaching environment and give them suggestions for their career development (Hudson, 2010).

For all these four functions of mentoring, they have shown the responsibilities of mentors and the achievement of mentoring system in education. Fresh teachers with great satisfaction in the first stage of their teaching career will make more contribution to their universities in the future.

On the other hand, mentors can also be benefit from the mentoring system in the industry of education. It might strength their mid-career development and make educational institutions more stable to some extent. Indeed, a higher turnover rate comes from mid-career teachers. The reason is that without the original passion, the boring and repetitive work left would bring them into a confused period that academic and teaching achievements would be ignored. (Bressman, Winter \& Efraon, 2018). Once they become mentors, during the mentoring progress, they can gain new challenges and the feeling of freshness will be aroused. In addition, previous empirical research has reported that the mentoring relationship can improve a mentor's career fulfillment and satisfaction, creative collaborative work, career rejuvenation and new ideas from mentees and have loyal followers (Johnson, 2003). Darwin \& Palmer (2009) argue that individual development highly relies on the mutual action among colleagues and their bosses, especially the mentoring relationships. Thus, the mentoring for both mentors and mentees is the mutual learning process in order to achieve win-win.

\section{How to Establish An EFFECtive Mentoring SYSTEM IN UNIVERSITIES}

The most important task to establish an effective mentoring system in universities is to select the right mentors. Previously for the traditional mentoring programs, organizations prefer to choose senior and junior experienced employees or managers to be mentors because most people generally believed that "jiang hai shi lao de la" (the older is more knowledgeable and professional) (Bressman, Winter \& Efraon, (2018). However, in recent years organizations tend to reduce the number of middle and old mentors to coach employees and peer mentoring has gradually become normal in organizations (Bryant, 2005). As there is no generation gap between peers, the interactive relationship between mentors and mentees might be more effective. More importantly, peers with similar growing background are much easier to transform tacit know-how to explicit know-how in mentoring process, and then create new knowledge and ideas, especially for the peer mentoring within young people who are more creative (Bryant, 2005). Therefore, universities can apply this strategy to build an effective mentoring system.

In addition, universities should notice that not all the experienced teachers can be mentors since mentors also need to be coached in the aspect of morality, professional knowledge and teaching skills (Hudson, 2013). As previous mentioned that mentors may benefit from mentoring process, it is important to recognize that university administrators should be cautious in choosing mentors and ensuring mentors who have no ethical issues (Bryant, 2005). Also, Bushardt, Moore \& Debnath (1982) indicate that as referred to choose the mentor, the person who can assist the mentee should also get the assistance from the mentee, and the person has mentee's confidence and the person have positive track record during their working period.

Then, it can organize a group of mentors. Ramani, Gruppen \& Kachur (2006) provide twelve suggestions to develop effective mentors. 1. Mentors should clearly know their position in mentoring process and their skills of 
listening and feedback need to be improved because the mentoring skills are not natural but should be trained. 2 . Mentors should be aware of gender issues and culture. It is not mandatory for mentors and mentees to match through gender and culture, but accessible for those who aspire it. 3. Mentors should not only encourage their mentees but also challenge them. If mentors only support their proteges without any challenges, their proteges may not be improved quickly and professionally; contrarily, excessive challenges to the proteges or few supports may lead them to be depressed in the initial stage of their professional growth. 4. Universities need to provide a platform for mentors to confide their uncertainties and issues because this platform can offer opportunities for mentors to discuss problems and communicate experiences during their mentoring process in order to get more valuable suggestions. 5. Mentors should be reminded that they need to have professional boundaries to avoid excessively close relationships with mentees such as personal affection between men and women. 6. Mentors should also be mentored to develop their mentoring skills, enrich their current knowledge and relieve their pressure. 7. Mentors should be recognized and focused on their value of mentoring, and then they will feel meaningful and satisfied during doing mentoring task. 8. Mentors should be rewarded then they can contribute more to universities, such as extra material and spiritual rewards. 9. Mentors should be given more free space to fulfill their mentoring task effectively. 10 . Mentors should not be designed to play psychologist to deal with mentees' personal issues because they are not professional in this field. 11. As mentioned above universities should apply the programs of peer mentoring as far as possible. 12. The mentoring programs should be continuously evaluated in order to ensure its effectiveness. These twelve tips can effectively help universities to build a perfect mentoring system.

However, there are some challenges when universities tend to establish a mentoring system. Universities should notice that they may not have enough professional and experienced teachers to be mentors because not everyone is qualified. Thus, universities should coach and cultivate enough mentors as early as possible, and to introduce external experts to supplement the team of mentors (Hudson, 2013). Furthermore, universities should also notice that not every one desires to be mentors (Darwin \& Palmer, 2009; Allen, Russell \& Maetzke, 1997). As a result, universities should formulate some strategies to encourage more teachers be mentors, such as the promotion system of mentoring.

\section{CONCLUSION}

To increase the competitive advantages of Chinese private universities, the key point is the quality of teachers and their professional development. This article provides an effective way to improve teachers' quality and their professions, which has provided references to establish a positive and effective mentoring system. Mentoring system can not only help beginning teachers to involve into their universities' culture and accept it, transform teaching knowledge and skills to them, and provide suggestions for their following career development, but also improve experienced and skilled teachers to be more satisfied if they become mentors. In addition, this article provides many suggestions for Chinese private universities to know the ways for establishment of an effective mentoring system clearly. Consequently, if some Chinese private universities can establish the mentoring system and apply it into their management, they will develop faster and be more competitive than other public universities.

\section{REFERENCES}

[1] Allen, T. D., Russell, J. E., \& Maetzke, S. B. (1997). Formal peer mentoring: Factors related to protégés' satisfaction and willingness to mentor others. Group \& Organization Management, 22(4), 488-507.

[2] Bressman, S., Winter, J. S., \& Efron, S. E. (2018). Next generation mentoring: Supporting teachers beyond induction. Teaching and Teacher Education, 73, 162-170.

[3] Bryant, S. E. (2005). The impact of peer mentoring on organizational knowledge creation and sharing: An empirical study in a software firm. Group \& Organization Management, 30(3), 319-338.

[4] Bushardt, S. C., Moore, R. N., \& Debnath, S. C. (1982). Picking the right person for your mentor. Advanced Management Journal, 47(3), 46-51.

[5] Darwin, A., \& Palmer, E. (2009). Mentoring circles in higher education. Higher Education Research \& Development, 28(2), 125136.

[6] Eby, L. T., Durley, J. R., Evans, S. C., \& Ragins, B. R. (2006). The relationship between short-term mentoring benefits and long-term mentor outcomes. Journal of Vocational Behavior, 69(3), 424-444

[7] Fagenson, E. A. (1988). The power of a mentor: Protégés' and nonprotégés' perceptions of their own power in organizations. Group \& Organization Studies, 13(2), 182-194

[8] Hudson, P. (2013). Mentoring as professional development: 'growth for both' mentor and mentee. Professional development in education, 39(5), 771-783

[9] Hudson, P. B. (2010). Mentors report on their own mentoring practices. Australian journal of teacher education, 35(7), 30-42.

[10] Johnson, W. B. (2003). A framework for conceptualizing competence to mentor. Ethics \& Behavior, 13(2), 127-151

[11] Kemmis, S., Heikkinen, H. L., Fransson, G., Aspfors, J., \& EdwardsGroves, C. (2014). Mentoring of new teachers as a contested practice: Supervision, support and collaborative self-development. Teaching and teacher education, 43, 154-164.

[12] Memon, J., Abd Rozan, Z., Uddin, M., \& Shah, A. (2013). Selecting a mentor: Guide for a protégé. World Applied Sciences Journal, 24(6), 732-738.

[13] Mena, J., Hennissen, P., \& Loughran, J. (2017). Developing preservice teachers' professional knowledge of teaching: The influence of mentoring. Teaching and Teacher Education, 66, 47-59.

[14] Nash, C. (2003). Development of a mentoring system within coaching practice. Journal of Hospitality, leisure, sport and tourism education, 2(2), 39-47.

[15] Ramani, S., Gruppen, L., \& Kachur, E. K. (2006). Twelve tips for developing effective mentors. Medical teacher, 28(5), 404-408.

[16] Richter, D., Kunter, M., Lüdtke, O., Klusmann, U., Anders, Y., \& Baumert, J. (2013). How different mentoring approaches affect beginning teachers' development in the first years of practice. Teaching and Teacher Education, 36, 166-177.

[17] Wilson, J. A., \& Elman, N. S. (1990). Organizational benefits of mentoring. Academy of Management Perspectives, 4(4), 88-94. 